\title{
A palavra (não) tomada: enunciação e oralidade no ensino-aprendizagem de Francês Língua Estrangeira (FLE)
}

\section{The word (not) taken: enunciation and orality in teaching-learning French as a Foreign Language (FLE)}

Carla Nunes Vieira Tavares*

*Universidade Federal de Uberlândia (UFU), Uberlândia, Minas Gerais / Brasil carlatav@ufu.br

https://orcid.org/0000-0002-5156-0150

Isabel Silva Alves Quintino**

**Universidade Federal de Uberlândia (UFU) Uberlândia, Minas Gerais / Brasil isabelquintino2201@gmail.com

https://orcid.org/0000-0003-1475-7875

RESUMO: Discutiremos a prática da oralidade na sala de aula a partir da perspectiva discursivo-enunciativa (LEITE, 2015) e da discursiva sobre o ensino-aprendizagem de línguas (CORACINI, 2002). Objetivamos analisar os efeitos de práticas pedagógicas embasadas na abordagem acional (actionnelle), em um curso de francês língua estrangeira (FLE) de uma universidade federal, na promoção do que chamamos de tomada da palavra por parte do aluno, a partir da análise de cenas enunciativas (CE). Os resultados apontam para a injunção do aspecto contingencial de sala de aula, tornando-o, muitas vezes, mais premente do que as declarações do professor e configurando-se como cerceador dos mo(vi)mentos que alguém precisa empreender para construir e se apropriar de um espaço enunciativo LE.

PALAVRAS-CHAVE: subjetividade; ensino-aprendizagem de FLE; oralidade; enunciação.

ABSTRACT: This article discusses the oral practice in the classroom through the discursive- enunciative perspective. We aim to analyze the effects of pedagogical practices which are said to be based on the action approach (actionnelle) in a course of French as Foreing Language (FLL), at a federal university, during the promotion of what we call student's word taking. The results point to the imposition of the contingency aspect in the classroom, often making it more urgent than the teacher's declarations and efforts, thus 
establishing itself as a restrictor of movements that one needs to undertake in order to build and occupy an enunciative space in this language.

KEYWORDS: subjectivity; teaching-learnign FLE; orality; enunciation.

\section{Introdução}

Devido à relevância conferida à competência oral na LE no imaginário de alunos e professores (SANTOS; GUILHERME, 2011), este artigo problematiza o trabalho com a oralidade geralmente promovido em aulas de língua francesa (FLE) embasadas na abordagem acional (actionnelle), em um curso oferecido por um Centro de Línguas Estrangeiras de uma Universidade Federal mineira. Discutimos em que medida algumas práticas pedagógicas podem (ou não) propiciar uma tomada da palavra nessa língua, ou seja, a construção de um espaço enunciativo na língua do outro, adotando uma perspectiva discursivo-enunciativa. A pergunta motivadora indaga sobre qual trabalho com a oralidade é promovido em uma sala de aula de língua francesa que propiciaria a instauração de processos identificatórios entre sujeito-língua e ensejaria uma tomada da palavra em FLE. A abordagem acional é declarada como norteadora majoritária das práticas de professores de FLE em cursos de línguas e no documento do Cadre Européen Commun de Référence pour les langues (CECR), por priorizar a comunicação e a interação social mediada pela língua-alvo. Consequentemente, há uma expectativa tanto por parte de alunos como de professores de que a competência oral seja o foco primordial dessas aulas. Objetivamos, neste trabalho, discutir os efeitos das práticas pedagógicas do professor que declara adotar essa abordagem para promover a oralidade, a partir da análise discursiva de cenas enunciativas (CE). ${ }^{1}$

O viés teórico-metodológico discursivo-enunciativo adotado possibilita que o foco de análise recaia na relação sujeito-língua e nos seus desdobramentos para o que dela se materializa na sala de aula, neste caso, o discurso e as relações empreendidas pelo aluno com a língua mediadas pelo professor. Nesse sentido, são fundamentais os trabalhos benvenistianos, pois o discurso é responsável pelo processo, produção e reprodução das relações entre interlocutores na sociedade por meio da linguagem. Assim, refere-se ao meio pelo qual os homens manejam a língua e organizam a vida

${ }^{1}$ Veja tópico 2. 
em sociedade, sendo atravessados por historicidade, cultura e subjetividade. O discurso estabelece possibilidades diversas e intercambiáveis de ocupação de posições discursivas, na dependência dos modos de enunciação que se desenrolam a partir delas. Por sua vez, a enunciação é da ordem do irrepetível, pois coloca "em funcionamento a língua por um ato individual de utilização" (BENVENISTE, (2006, p. 82). O binômio discurso e enunciação nessa relação de batimento permite pensar a sala de aula como instância discursiva (LEITE, 2015) na qual a enunciação se desenrola a partir da historicidade e subjetividade constitutivas de professores e alunos, indiciadas nos dizeres e nos movimentos empreendidos no processo de ensino-aprendizagem. Consequentemente, é possível problematizar o funcionamento dos discursos na/da sala de aula e seus efeitos na constituição subjetiva dos envolvidos, para, então, discutir a prática pedagógica (GOMES, 2013). Enseja-se, assim, o deslocamento do enfoque nas questões estritamente cognitivas e metodológicas, possibilitando-nos conceber a relação sujeito-língua como da ordem da subjetividade ${ }^{2}$ e, por isso mesmo, complexa no que concerne à tomada da palavra na LE.

Este artigo, então, problematiza, primeiramente, a noção de oralidade na Didática de Línguas Estrangeiras (DLE) e seus limites no que tange à consideração da subjetividade no ensino-aprendizagem. Em seguida, analisa discursivamente CECR, documento que traça diretrizes para o ensino de línguas na Europa e influencia grandemente as ações de cursos de línguas no Brasil, bem como dos professores. Após breve descrição da pesquisa e delimitação do recorte aqui contemplado, discutimos os resultados dos gestos de análise do corpus e propomos algumas considerações.

\section{Oralidade e tomada da palavra}

A fim de entender os sentidos abarcados pela expressão tomada da palavra, analisamos partes do CECR que versam sobre o tema, pois o documento está embasado em teorias da DLE e é um dos instrumentos didático-pedagógicos de constituição de professores e alunos de FLE.

\footnotetext{
${ }^{2}$ Embora a perspectiva teórico-metodológica embasadora deste trabalho permita considerações mais abrangentes sobre o campo discursivo de ensino-aprendizagem de FLE no país, neste artigo optamos por delimitar nossa problematização a aspectos da subjetividade e aos processos identificatórios analisados nas CE, por questões de espaço.
} 
Consequentemente, o discurso do CECR pode impactar substancialmente os discursos na/da sala de aula, pois, além de estabelecer objetivos em relação à competência oral em cada nível (A1, A2 etc.), direcionam a produção de livros didáticos, amplamente utilizados em aulas de FLE. Não intentamos desvalorizar a relevância dos instrumentos didático-pedagógicos para a prática de sala de aula; antes, por afetarem a formação dos professores e suas práticas, propomos refletir e problematizar suas implicações sobre o trabalho com a oralidade para a prática pedagógica. Nossa aposta, neste ponto, é que a abordagem acional apoia-se na comunicativa, mas contrapõese a ela, porque objetiva fazer operar a noção de língua, de interação e de comunicação em um enquadre mais social. Trata-se, porém, de um conjunto de discursividades fortemente marcado pela interdiscursividade ${ }^{3}$ da abordagem comunicativa, permitindo problematizar alguns dos pressupostos nos quais ambas se baseiam.

Os discursos sobre a competência comunicativa e a abordagem comunicativa na LA, compartilhados pelas teorias da DLE, significaram um avanço nos estudos da linguagem, sobretudo no ensino-aprendizagem de línguas. Eles tiveram grande influência na proposição da abordagem acional, amplamente adotada no FLE.

A premissa inicial de que a língua é um instrumento de comunicação e consiste, portanto, em uma ferramenta fundamental para a interação, deslocou-se para entendê-la como meio dinâmico de produção de sentidos na dinâmica complexa da interação. Assim, enfatiza-se nas ações pedagógicas de ensino de línguas a possibilidade de considerar a negociação dos sentidos como central no processo de tornar os alunos interlocutores na tomada da palavra em LE. O ensino-aprendizagem da língua-alvo tem como meta central, então, possibilitar a interação por ela mediada na sociedade.

Para a abordagem acional, ensinar uma língua estrangeira é proporcionar aos aprendizes o desenvolvimento de suas potencialidades e a otimização de suas capacidades por meio de tarefas complexas. Origina-se aí uma primeira diferença entre a abordagem comunicativa e a acional, de acordo com Rosen (2009, p. 8):

\footnotetext{
${ }^{3}$ Interdiscurso é uma noção da Análise de Discurso Pecheutiana, que se refere ao já-dito, ao pré-construído discursivamente, que possibilita a produção de discursividades e de efeitos de sentido (PÊCHEUX; FUCHS, 1997).
} 
(...) a articulação entre a abordagem comunicativa e a perspectiva acional [seria]: a passagem de uma aprendizagem individual (que podemos associar à concentração no aluno, característica da abordagem comunicativa que se dá perfeitamente na realização dos jeux de rôles, ${ }^{4}$ diálogos, e das simulações) para uma aprendizagem colaborativa e solidária pautada em um agir social e comunicacional (que podemos associar, para fazer um paralelo, a uma concentração no grupo que encontra sua expressão na pedagogia do projeto)..$^{5}$

Daí a ideia no CECR de um aluno como ator social, criando, portanto, uma dimensão de "jogo social" autêntico diferenciando a co-action (agir com os outros durante o tempo da aprendizagem) da simulation (técnica de base utilizada pela abordagem comunicativa). Nisso consiste outra diferença que, para a DLE, coloca a abordagem acional como mais vantajosa para a aprendizagem do que a abordagem comunicativa, pois promove principalmente o falar com e o agir sobre os interlocutores.

A abordagem acional possui duas concepções fundamentais baseadas nesses pressupostos, quais sejam: a tarefa e a ação. A primeira concerne aos movimentos do aprendiz para comunicar. Diferentemente do comumente proposto pelo jeu de rôles, comum na abordagem comunicativa, as tarefas são preconizadas como voltadas para o contexto mais imediato do aluno. Devem propor ações comunicativas a partir de uma necessidade detectada como real, plausível ou autêntica no entorno comunicativo do aluno, resultando em uma produção linguageira observável. As tarefas, conforme Rosen (2009, p. 83), propõem um quadro interacional que requer dos alunos "a construção de competências linguageiras adaptadas às situações de comunicação autênticas". 'Já a ação, segunda concepção importante da abordagem acional, relaciona-se ao que o ator - aquele que desempenha as

\footnotetext{
${ }^{4}$ Jogo de papéis (ou role play).

${ }^{5}$ Texto original: [...] l'articulation entre approche communicative et perspective actionnelle: le passage d'un apprentissage individuel (que l'on peut associer à la centration sur l'apprenant, caractéristique de l'approche communicative et qui s'exerce parfaitement lors des jeux de rôles et des simulations) à un apprentissage colaboratif et solidaire misant sur un agir social et communicationel (que l'on peut associer, pour tenter la parallèle), à une centration sur le groupe qui trouve son expression dans la pédagogie du projet).

${ }^{6}$ Texto original: "construire des compétences langagières adaptées à des situations de communication authentique".
} 
tarefas - realiza na sociedade concreta, a partir do estabelecimento de uma parceria com seu interlocutor (PUREN, 2002).

Entretanto, embora tente discursivamente se distanciar da abordagem comunicativa, é possível perceber pontos nos quais a abordagem acional se deixa afetar pela primeira. Em ambas há uma ênfase no que é considerado como real e autêntico e na negociação de sentidos, ainda que, na acional, esse ideal esteja relacionado à execução de tarefas comunicativas. Estranha-nos, porém, a dissociação do sentido de processo, também em jogo nas atividades propostas pela abordagem comunicativa, como o jeu de rôles.

No CECR, inclusive é recorrente o termo "comunicação eficaz", preconizada como possível mediante uma adaptação das formas linguísticas à "situação de comunicação". Trata-se de considerar a relação da forma com o contexto da comunicação - como o estatuto do interlocutor, idade, posição social e lugar físico -; e com a "intenção de comunicação", ou seja, o que se deseja comunicar, ou função linguageira, tal como: pedir para identificar um objeto, pedir uma permissão, dar ordens, dentre outros (GERMAIN, 1993). Nesse sentido, comunicar estaria para a ordem de uma produção de enunciados linguísticos considerando, por um lado, a "intenção de comunicação" e, por outro, a "situação de comunicação". A relação entre esses dois planos, para a abordagem acional, é essencial na competência de comunicação. O sentido é entendido como a resultante de uma negociação entre dois interlocutores (GERMAIN, 1993).

Podemos ver, no entanto, mais uma aproximação entre a abordagem comunicativa e a acional, na medida em que o conceito de comunicação na primeira se relaciona ao de intenção, tal como preconiza a segunda. Trim (1984, p. 123), autor que muito contribuiu com a elaboração teóricometodológica da abordagem comunicativa, postulava que um comunicador efetivo na língua estrangeira deve munir-se do conhecimento do sistema linguístico, de suas funções e das condições de seu uso, a fim de realizar suas intenções comunicativas em situações cotidianas, o que está bastante alinhado com a proposta da abordagem acional.

${ }^{7}$ Devido à recorrência no CECR das expressões aspeadas, as páginas em que aparecem não foram referenciadas. 
A fim de capacitar "um utilizador da língua [para que] se engaje em um ato de comunicação"s (CECR, 2000, p. 46), o documento sinaliza temas privilegiados para os "atos de comunicação" (p. 9) e tarefas comunicativas com finalidades definidas. Objetiva-se possibilitar que o aprendiz esteja apto a um "comportamento linguageiro eficaz" (p. 9). A oralidade em LE, portanto, se assemelha a um produto ansiado, com características delineadas e objetivos definidos, que visa à eficiência e à possibilidade de atingir uma competência. As ansiadas eficiência e competência comunicativa, por sua vez, estão relacionadas não só à precisão e correção no nível sistêmico ou à habilidade comunicativa, mas, também e principalmente, à ação colaborativa inerente à interação verbal, adequação ao registro, validade dos dizeres envolvidos em uma situação comunicativa, possibilidade de troca de significados, dentre outros elementos.

Embora estudos mais recentes sobre a abordagem acional e comunicativa (BENTO, 2013; VALÉRIO; MAT'TOS, 2018) atribuam à língua a função de mediadora de práticas sociais na produção de sentidos, ${ }^{9}$ ainda são recorrentes efeitos de sentido que reforçam um caráter instrumental e puramente pragmático ao ensino-aprendizagem de FLE no CECR. Palavras como "tarefas", "formulação de necessidades", dentre outras presentes do CECR, acabam por reforçar uma ênfase no ensino-aprendizagem na provisão de meios para alcançar os fins. A noção de língua como "um objeto externo ao sujeito, do qual este pode se servir para determinados fins" (FRANZONI, 1991, p. 63) é reafirmada. Consequentemente, se os aprendizes, enquanto "atores sociais" (cf. CECR, 2000), forem capacitados para a produção do comportamento linguageiro adequado a cada situação, expostos ao conhecimento linguístico necessário e conseguirem, desse modo, se engajarem nos diversos atos de comunicação previstos pelas tarefas que cumprem os requisitos da abordagem comunicativa ou acional, provavelmente desenvolverão uma oralidade que pode ser considerada fluente e eficiente.

As palavras "utilizador" e "ato de comunicação", destacadas anteriormente, acirram o utilitarismo que perpassa a noção de língua e de

\footnotetext{
${ }^{8}$ Texto original: "Un utilisateur de la langue s'engage dans un acte de communication..." (grifos nossos).

9 Trabalhos sobre FLE referem-se a uma derivação da abordagem acional denominada "pluriacional" (BENTO, 2013).
} 
comunicação contidas no documento. Por um lado, o termo utilizador pode remeter ao reducionismo da consideração de que o aprendiz se serve da língua por uma necessidade específica que tenha. Semelhantemente, o termo ato de comunicação, como é enunciado no documento, remete à ideia do uso da linguagem de forma pragmática, a fim de mediar significados para um propósito específico. Entretanto, o não engajamento por parte de alguns aprendizes nas tarefas comunicativas pode se dar, seja porque a necessidade do aprendiz não coincide com a do contexto situacional apresentado, seja porque a necessidade criada não toca o desejo do sujeito, ou nem mesmo o aprendiz tenha consciência de qual seja sua necessidade. As interações aí abarcadas podem se limitar unicamente ao "contexto conversacional", ignorando que, na interação, há uma dimensão para além do explícito ou implícito nas "situações face a face" (CECR, 2000, p. 32): a subjetividade. Enquanto utilizador da língua, o aluno poderá enfrentar dificuldades até mesmo para fazer uso da palavra, não se inscrevendo subjetivamente naquilo que reproduz.

Os pressupostos teórico-metodológicos que perpassam tanto a abordagem comunicativa como a abordagem acional constituem discursividades com algumas implicações para o ensino de LE, merecedoras de problematização visando pensar os mo(vi)mentos de tomada da palavra na aula de língua estrangeira e a incidência da subjetividade nesse processo. Utilizamos essa grafia devido a dois dos sentidos que a configuração proposta nos permite. A primeira diz respeito ao movimento do sujeito na direção de apropriar-se ou não da língua; a segunda refere-se ao momento em que essa apropriação (não) se dá, sendo, portanto, da ordem do singular, do tempo próprio do sujeito, conforme já exposto na introdução deste trabalho. Ao enunciar, "[...] o sujeito trabalha a língua, ao mesmo tempo em que a língua trabalha o sujeito" "(ANDERSON, 1999, p. 107), essa relação não só passa pelo corpo, como, também, marca o corpo de quem se lança no confronto de (se) enunciar na língua do outro.

Consequentemente, se os aprendizes, enquanto "atores sociais" (cf. CECR, 2000), forem capacitados para a produção do comportamento linguageiro adequado a cada situação, expostos ao conhecimento linguístico necessário e conseguirem, desse modo, se engajar nos diversos atos de comunicação previstos pelas tarefas que cumprem os requisitos da

${ }^{10}$ Texto original: "[...] le sujet travaille la langue autant que la langue travaille le sujet." 
abordagem comunicativa ou acional, provavelmente desenvolverão uma oralidade que pode ser considerada "fluente" e "eficiente".

$\mathrm{Na}$ perspectiva discursivo-enunciativa, essa noção de língua não sustenta sua função de constituir o sujeito e lhe inserir no simbólico e no social, na medida em que é pela língua que o homem assimila a cultura, a perpetua ou a transforma (BENVENISTE, 2005, p. 32). Ademais, a língua porta o equívoco, na medida em que "todo enunciado é intrinsicamente suscetível de tornar-se outro, diferente de si mesmo, se deslocar discursivamente de seu sentido para derivar para um outro" (PÊCHEUX, 2012, p. 53). O equívoco constitutivo da língua mostra seu efeito no funcionamento da linguagem através de marcas, aparentes ou não, no dizer. Cabe ressaltar, inclusive, que a equivocidade da língua está presente em toda interação, o que evidencia a dificuldade em considerar a língua como algo unívoco e externo ao sujeito. Falar em comunicação nessa perspectiva, portanto, implica, também, a não comunicação, uma vez que a língua não é homogênea e, menos ainda, transparente. Significa, ainda, considerar o imprevisto, o inesperado, aquilo que fura toda e qualquer possível intenção do interlocutor, como parte da produção de efeitos de sentidos nas práticas linguageiras. O equívoco, a contradição, a ambiguidade e o furo são elementos normalmente higienizados nos processos de ensinoaprendizagem de línguas estrangeiras, pois, além de serem considerados como "erros" ou "desvios" desestabilizadores da comunicação, ameaçam o controle do professor sobre o processo e a percepção do aluno acerca de seu progresso rumo à fluência almejada. Reside aí o primeiro ponto de articulação entre a problematização aqui empreendida sobre o documento do CECR e os gestos de análise das CE. A noção de língua ali mobilizada pouco contempla mo(vi)mentos subjetivos para a tomada da palavra em FLE.

Uma questão, portanto, pouco considerada pela DLE é o processo de subjetivação pelo qual o aluno passa no mo(vi)mento de se ver inscrito e de se inscrever nas discursividades de uma determinada língua. A didática, os métodos e abordagens auxiliam, certamente, o aluno na aprendizagem; porém, nem sempre são "eficazes" e/ou ensejam uma "aprendizagem significativa" ${ }^{11}$ envolvendo a tomada da palavra. Ao apostarmos na

\footnotetext{
${ }^{11}$ Conceito elaborado por Ausubel em 1968, representante do cognitivismo. Refere-se ao processo pelo qual uma informação se relaciona a um aspecto relevante da estrutura de conhecimento do indivíduo, mediante a interação com uma estrutura de conhecimento
} 
complexidade e tensão que marcam o contato entre aluno e LE, nos contrapomos à aprendizagem significativa estritamente cognitiva que preconiza o uso da palavra. Considerar a subjetividade no processo implica pensá-lo sempre aberto, tendo como interlocutores sujeitos fal(t)antes e, consequentemente, contar com a impossibilidade de tudo dizer, de tudo controlar, de tudo satisfazer, de tudo saber. De saída, uma segunda articulação dessa discussão com a análise no próximo tópico aponta para a instauração de uma postura questionadora quanto ao todo da comunicação, à intenção como plena e norteadora das práticas linguageiras e à possibilidade de uma proficiência ideal. Em contrapartida, instaura-se a dependência da aquiescência em subjetivar-se pela e na LE para que uma aprendizagem significante seja possível.

Segundo De Nardi (2002), tomar a palavra significa assumir um lugar, uma posição de sujeito que se inscreve no discurso, ao mesmo tempo em que o produz, evitando, assim, que o dizer seja uma simples reprodução, um acúmulo de frases feitas, ${ }^{12}$ em que alguém imita o outro, mas não se propõe como sujeito nessa língua. Tomar a palavra na LE, portanto, implica identificações - um dos processos de subjetivação - com e nessa língua que impulsionem o aprendiz a realizar um trabalho sobre si, uma escuta e um distanciamento de si para tornar-se outro. Identificar-se com a língua remete ao caráter de objeto de investimento subjetivo que, neste caso, a língua, enquanto saber, pode ocupar; identificar-se na língua remete à resultante desse investimento, indiciando que algo de uma aprendizagem significante se deu.

É nessa dimensão que a tomada da palavra se configura, na medida em que "aprender uma língua é sempre um pouco, tornar-se um outro" (REVUZ, p. 227) e possibilita a construção de um lugar enunciativo na

específico (conceitos subsunçores ou, simplesmente, subsunçores (subsumers), existente na estrutura cognitiva do indivíduo. A aprendizagem só é significativa se o conteúdo descoberto se ligar a subsunçores relevantes já existentes na estrutura cognitiva. Promover uma aprendizagem significativa implica utilizar questões e problemas novos para os aprendizes, a fim de que não simulem uma suposta aprendizagem com respostas mecanizadas. Ou ainda, propor tarefas de aprendizagem que dependam de outras e que só podem ser executadas com perfeito domínio das precedentes. (MOREIRA, 1982).

${ }^{12}$ Compreendemos frases feitas como aquelas que se assemelham a expressões mecanizadas e cujos sentidos encontram-se cristalizados. 
língua outra, do qual e no qual o aluno possa ser dito e se dizer. Filiamo-nos, portanto, à Serrani (p. 146), que propõe a tomada da palavra como

[...] aquela que excede a ordem da instrumentalidade da língua e os sentidos excedem a ordem da proposição lógica, é a tomada de palavra que afeta e transforma o sujeito como tal, pois linguagem e constituição subjetiva estão intimamente ligadas.

Essas noções nortearão nossas considerações sobre os modos de promoção da oralidade e os possíveis efeitos para a tomada da palavra por parte do aluno em aulas de FLE.

\section{$2 \mathrm{O}$ recorte da pesquisa e os gestos de análise}

A pesquisa da qual derivou este trabalho se deu no Centro de Idiomas de uma Universidade Federal mineira. Após a aprovação do Comitê de Ética em Pesquisas com Seres Humanos da Universidade, as aulas de um semestre do curso de FLE de nível B1 ${ }^{13}$ foram observadas e filmadas. O corpus aqui analisado é composto da transcrição de cenas enunciativas (CE) resultantes da filmagem.

Para o nível limiar da turma enfocada, duas competências são apregoadas como essenciais: a capacidade para manter uma interação e chegar ao que se quer em contextos variados; e a capacidade de lidar com problemas da vida cotidiana (CECR, 2000). Teoricamente, esse deveria ser o nível dos alunos na turma analisada. Todavia, a constatação dos variados níveis de aprendizagem na mesma classe acirrou ainda mais o entendimento de aprender a demanda de cada um e sua maneira singular de inscrição na língua e o fato de ela ocorrer em momentos diferentes, não controlados nem pelo professor nem pelo próprio aluno.

Entendendo o discurso como um funcionamento que produz efeitos, um viés dos gestos de análise sobre o corpus analisa as identificações no discurso, apontando modos de relação entre sujeito e língua indiciadores de como o trabalho com a oralidade em aulas de FLE propicia a tomada da palavra. Para tanto, o olhar analítico buscou marcas de subjetividade

\footnotetext{
${ }^{13}$ Identificado também como o niveau seuil, ou nível limiar, o termo B1, estabelecido pelo CECR, por si só, não diz muito. Na linha cronológica da aprendizagem do francês, ele se encontra entre os níveis A2 (nível intermediário ou de sobrevivência) e B2 (nível avançado ou do "utilizador independente").
} 
inscritas na materialidade discursiva e em aspectos não-verbais que apontam para traços de identificações inconscientes do sujeito à língua; e para os modos como o sujeito singulariza essa relação, indiciando movimentos de identificação na língua. Privilegiamos, então, a recorrência de temas discursivizados, a reformulação e a equivocidade materializados no dizer.

Paralelamente, outro viés da análise recai sobre os mo(vi)mentos enunciativos. $\mathrm{O}$ sujeito, ao se identificar a aspectos da língua, se assujeita a uma dada posição nessa língua e é nela e a partir dela que passa a se inscrever nessa nova ordem discursiva (TAVARES, 2002). Em outras palavras, para remetermo-nos a Benveniste (2005), identificar-se na e ao FLE pressupõe converter essa língua em discurso e, assim, propor-se como sujeito. Entretanto, isso não é algo simples, pois requer uma apropriação da língua pelo locutor, que não se reduz a colocar-se em primeira pessoa no dizer. Apropriar-se aponta para que o locutor consiga operar sobre a língua, ao mesmo tempo em que sofre os efeitos da operacionalização da língua sobre si, subjetivando-se por e através dela, deslocando-se, portanto, do dizer mecanizado para dizeres que digam de si e sobre si. Ao analisar os mo(vi)mentos enunciativos delineados nas CE, valemo-nos das noções de semantização e sintagmatização (desenvolvidas na análise), conforme os trabalhos benvenistianos, a fim de trilhar os efeitos das práticas pedagógicas no ensejo da tomada da palavra e em que medida o sujeito se deixa (ou não) tomar por ela.

A proposta de designar os recortes da transcrição como "cenas enunciativas" redundou de duas questões relativas à nossa filiação teórica. A primeira remete à nomeação "atores" atribuída aos interlocutores envolvidos nas tarefas e ações comunicativas pressupostas na abordagem acional. As cenas enunciativas propõem dar consequência aos efeitos de sentido produzidos por esta designação, bem como problematizá-la. A segunda questão pretende marcar que o dizer não só se materializa pelo falar, mas, também, é apreendido pelos aspectos não-verbais relacionados a gestos, expressões faciais, reações corporais dos alunos e do professor. Tais aspectos remetem para instâncias do sujeito que "geralmente não colaboram, nem mesmo convivem em harmonia” (REVUZ, 2001); entretanto, é esse sujeito que enuncia, e o modo como o faz convoca, também, o seu corpo. Cabe, ainda, ressaltar que nossas considerações de análise não se voltam para as pessoas envolvidas nas cenas, mas para os modos de ocupação da posição sujeito a elas assinalada, para a particularidade dessa ocupação, na 
dependência do investimento subjetivo e da consequente subjetividade em constante tensão.

\section{Corpo, língua e palavra}

Neste tópico, procedemos aos gestos de análise sobre os indícios da (não) tomada da palavra e aspectos da relação corpo-linguagem observados em uma das aulas. Indiciamos os mo(vi)mentos de tomada da palavra que podem ou não se dar na dinâmica da aula.

A aula teve como tema "Solo mais pas trop" [Só, mas não muito]. De acordo com o livro didático no qual a aula se embasava, o conteúdo sociocultural preconizava novas maneiras de encontrar a "alma gêmea" e a aula trabalhava uma situação de speed dating [namoro rápido]. O momento da aula que discutimos a seguir foi a proposta de um jeu de rôle apresentado pelo livro. Cada aluno teria sete minutos para se apresentar para uma das mulheres e vice-versa. Houve, no entanto, uma redução no tempo de apresentação para um minuto.

O primeiro mo(vi)mento observado foi a resistência de alguns alunos diante da atividade, o que desencadeou esta resposta da professora:

$\mathrm{P}$ - Vous pensez que vous seriez libre? Non.

D'abord ça sera les hommes que vont essayer de donner des argumentes pour convaincre, pour se présenter tout simplement. Après ça, ça sera à vous [se dirigindo para as mulheres], mais une minute, ça sera pas sept minutes [...] une minute pour chaque femme [...] Nous allons determiner les règles [...] vous dever. faire votre portrait, tout simplement [...] vous dîtes ce que vous intéressez dans la vie et argumentos para convencer, para se apresentarem. Depois serão vocês [se dirigindo para as mulheres] mas um minuto, não serão sete minutos [...] um minuto para cada mulher [...] Vamos determinar as regras [...] vocês devem fazer suas descrições [...] vocês dizem pelo quê se interessam na vida e assim cada mulher observa para ver se os gostos e as là, chaque femme observe pour voir si ses goûts et ses préferences sont les mêmes, c'est tout simplement ça [...] bon, pour simplifier, vous n'aimez pas tout cette... disons... ce rôle incroyable, vous aller donc dire à une seule personne, d'accord? [...] vous pouvez rester là, ce n'est pas nécessaire de vous mettre au centre, "tête à tête"

$\mathrm{P}$ - Vocês pensam que estão livres? Não. Primeiro os homens vão tentar dar preferências são as mesmas, é isso [...] bom, para simplificar, vocês não gostam desse papel incrivel, então, vocês vão dizer para uma pessoa apenas, tá certo? Vocês podem ficar onde estão, não é necessário se colocarem no centro, "cara a cara". 
O fato de a atividade não ser realizada tão livremente parece esvaziar a possibilidade de haver espontaneidade e autenticidade a partir de uma resposta do aluno à demanda apresentada. A pretensa liberdade necessária para que isso ocorra, advinda da espontaneidade e da autenticidade propagada pela abordagem acional, praticamente inexiste no ritual enunciativo da sala de aula, o que é explicitado na indagação retórica vinda da professora: "Vous pensez que vous seriez libre?". A expressão "ritual enunciativo" se refere ao esvaziamento do caráter de improvisação necessário a uma cena enunciativa (se nos filiarmos ao campo semântico do teatro para nos referir à palavra cena), restando apenas o ritual. Em um dos poucos momentos em que a palavra poderia ser tomada pelo aluno para dizer de si, o tempo é reduzido em favor da contingência do programa. A própria relação corporal implícita na interação pretendida, o colocar-se cara a cara, e que poderia tornar o jogo mais próximo da realidade, preconizada pela abordagem acional, é omitida. Na verdade, materializa-se o jogo de poder em sua relação com o saber, conforme os trabalhos foucaultianos, que perpassa toda sala de aula, em que, mesmo que o objetivo pretenso do professor e do curso seja promover a produção oral, a contingência da prática é mais forte. Assim, o tempo, a ordem e o ritual da aula parecem preponderantes em relação à possibilidade de o aluno se enunciar e ser enunciado pela língua, ou seja, ser tomado pela língua e tomar a palavra nela.

Na primeira CE, a resistência à artificialidade e ao cerceamento que marcam a atividade é indiciada, desta vez no dizer dos alunos:

\section{CE (1)}

A professora pergunta se os alunos conheciam a expressão speed dating. Os alunos Timóteo (T); João (J); Maria (M) e Gabriela (G) compõem a seguinte cena, juntamente com a Professora $(\mathbf{P}):^{14}$

${ }^{14}$ Nomes fictícios. 


\section{P: C'est l'homme qui se présente!}

$[\ldots]$

$\boldsymbol{M}:$ C'est la femme qui fait le choix?

J: Chaque homme, chaque fois/ il y a dans la salle seulement deux personnes: le présentateur/ l'homme et la femme?

$T:$ Non, c'est une salle avec tous le monde.

J: C'est... très FATIGUÉ...

[enquanto isso Timóteo pega uma cadeira para fazer a demonstração de como funciona o speed dating

M: Ab non Monsieur João! [expressão de indignação com a reação do João]

J: Très FATIGUÉ! [João acirra a sua opinião sobre o jogo]

$\boldsymbol{P}:$ fatigante/

$\boldsymbol{T}$ : [pegou a cadeira e se posicionou de frente com Maria] - Sept minutes/ [vira a cadeira para outra garota e diz] sept minutes [repete o gesto mais umas duas vezes]

$\boldsymbol{M}$ : Mais sept homme et sept femme [direcionando a explicação para João]

[...]

$J$ : Dans cette situation je serais célibataire pour tout ma viel

$\boldsymbol{M}$ : ab non... moi non

$\boldsymbol{T}:$ Je crois qu'ily a des autres manières pour trouver l'âme soeur

$\boldsymbol{M}$ : [Ao mesmo tempo em que Timóteo fala, Maria diz]: Non, mais c'est très intéressant/ c'est un jeu/

P: Monsieur, vous avez une opinion tout à fait différent de madame/ ouil à partir de votre façon d'observer j'ai vu que vous n'est pas d'accord avec l'opinion de madame

[...]

$\boldsymbol{G}$ : Je pense que cette chose DE coeur?

$\boldsymbol{P}:$ Du Coeur

$\boldsymbol{G}$ : Du coeur ne PAIT pas/PAI?

$\boldsymbol{P}:$ Ah... ne peut pas être?

$\boldsymbol{G}:$ Non ...

T: Ily a une petite possibilité de trouver l'âme soeur.

$\boldsymbol{P}$ : L'âme soeur [corrigindo a pronúncia do aluno]

$\boldsymbol{P}$ : [se dirigindo para Gabriela diz]: Mais vous ne croyezpas!
$\boldsymbol{P}$ : É o homem que se apresenta!

$[\ldots]$

$\boldsymbol{M}$ : É a mulher que faz a escolha?

$J$ : Cada homem, por vez/ há uma sala somente com duas pessoas/ o apresentador o homem/ e a mulher?

$\boldsymbol{T}$ : Não, é uma sala com todo mundo

$J:$ É... muito cansativo...

[enquanto isso Timóteo pega uma cadeira para fazer a demonstração de como funciona o "speed dating"]

$\boldsymbol{M}$ : A h não Senhor João! [expressão de indignação com a reação do João]

J: Muito CANS ADO!

$\boldsymbol{P}$ : cansativo/

$\boldsymbol{T}$ : [pegou a cadeira e se posicionou de frente com Maria] - Sete minutos/ [vira a cadeira para outra garota e diz] sete minutos/ [repete o gesto mais umas duas vezes]

$\boldsymbol{M}$ : Mas sete homens e sete mulheres [direcionando a explicação para José]

[...]

$J$ : Nessa situação en seria solteiro por toda a minha vidal

$\boldsymbol{M}$ : ab não... eu não

$\boldsymbol{T}$ : Acredito que existem outras maneiras de encontrar a alma gêmea

$\boldsymbol{M}$ : [Ao mesmo tempo em que Timóteo fala, Maria diz]: Não, mas é muito interessante/ é um jogo/ $\boldsymbol{P}$ : Senhor, você tem uma opinião diferente da Marial $\mathrm{sim} /$ a partir da sua maneira de observar eu vi que você não concorda com a opinião da Maria

$[\ldots]$

$\boldsymbol{G}$ : Eu penso que essa coisa dE coração?

P: Do coração

G: Do coração não PODE/ PODE? [pronúncia]

$\boldsymbol{P}:$ Ah... não pode ser?

$G:$ non...

$\boldsymbol{T}$ : Há uma pequena possibilidade de encontrar a alma gêmea

$\boldsymbol{P}$ : Alma gêmea [corrigindo a pronúncia do aluno]

$\boldsymbol{P}$ : [se dirigindo para Gabriela diz]: Mas você não acredita! 
Identificamos, na $\mathrm{CE}$ acima, pelo menos quatro mo(vi)mentos dos alunos.

O primeiro é a resistência de João configurada na dificuldade em compreender a viabilidade do speed dating e sua aplicação no jeu de rôles. Ele resiste em aceitar as explicações e em se ver inscrito na situação, dada a maneira como se refere a ela nos dizeres: "C'est... trèsfatigué... (...) Dans cette situation je serait célibataire pour tout ma vie." Nesse breve enunciado, observamos fortemente a semantização da língua evidenciada no jogo de interlocução estabelecida entre Timóteo, Maria, Professora e João. Para Benveniste, "a relação do locutor com a língua determina os caracteres linguísticos da enunciação" (BENVENISTE,] 2006, p. 82). O autor remete aos índices específicos e aos procedimentos acessórios mobilizados pelo locutor para produzir sentidos. Os primeiros são relativos às coordenadas (eu, tu, ele, aqui, agora), marcas de pessoa, tempo e espaço; os procedimentos acessórios referem-se a quaisquer expedientes morfológicos, lexicais ou sintáticos de que se vale o locutor para influenciar seu alocutário, e que conferem singularidade a cada ato de enunciação (MELLO, 2012).

"Ao empregar a língua para expressar sua relação com o mundo, o locutor faz uso dos índices específicos e dos procedimentos acessórios para marcar sua presença no discurso, constituindo um centro de referência interno à enunciação" (MELLO, p. 90). A esse arranjo que o locutor realiza na língua chamamos sintagmatização. Ele é singular porque a instância enunciativa é irrepetível, única e o aparelho formal da enunciação é, além disso, sempre reconfigurado dado, inclusive, a referência própria do eu que corresponde cada vez a um ser único, proposto como tal (BENVENISTE, 2005).

Assim, a relação do sujeito com a língua é individual e converge para o fato de que ele a mobiliza diferentemente, visando a uma semantização da língua, ora construindo um espaço enunciativo na língua do outro, ou seja, fazendo as integrações paradigmáticas (utilizando as possibilidades) e sintagmáticas; ora apenas reproduzindo frases feitas aprendidas dentro ou fora da sala de aula. Sendo assim, a tomada da palavra não pode ser compreendida na ordem de um todo, mas, considerando, também, o não todo, o que resta.

João indicia sua posição em relação à prática de speed dating a partir, primeiramente, de um juízo de valor, materializado pelo uso do verbo "é", e da relação de adverbialização e adjetivação (é... muito cansado), remetendo, 
principalmente, à regra da atividade (sete minutos para cada mulher). João comete um deslize ao dizer fatigué em lugar de fatigante, prova disso é a correção realizada. Contudo, o "erro" pode apontar para uma possível implicação do aluno com a discussão, que se materializa linguisticamente no equívoco no adjetivo fatigué. Assim sendo, podemos inferir que João remete à sua posição como sujeito diante da atividade. A forma como articula a expressão aponta para certo efeito de contraposição à prática em questão e, consequentemente, uma resistência à discussão do tema, o que não impede a tomada da palavra nessa instância da aula. Ao contrário, João agencia a língua para se propor sujeito e marcar na língua e pela língua como se sentia, pois, na forma fatigué fica o traço de sua posição como sujeito diante da atividade (cansado) e do efeito que ela produzia sobre ele (cansativa). Notamos, ainda, na filmagem, a expressão facial desmotivada de João e o modo como ele se mexia e se deixava esvair na carteira, corroborando o gesto de interpretação aqui pretendido.

A experiência de linguagem de João, portanto, é fortemente evidenciada nesse dizer pela forma como agencia as palavras, indiciando sua posição discursiva e subjetiva frente ao tema proposto e pelo suporte do corpo nesse agenciamento. Isso é possível porque, ao mesmo tempo em que há um agenciamento formal da língua por parte do sujeito, está em funcionamento, também, o semantismo social, por meio do qual é possível compartilhar com o outro os sentidos.

O segundo mo(vi)mento se dá no sentido oposto ao mo(vi)mento de João e se configura na empolgação de Maria. Diferentemente de uma resistência que se materializa por meio de adverbialização e adjetivação, o gesto parece se inscrever no e pelo corpo. Não que a ela faltassem competências linguísticas para produzir a frase em questão na língua francesa. Ao contrário, nas aulas ela sempre se dispõe a falar em francês. Mas, no auge da discussão, em que parece haver urgência em expressar-se, é o corpo de Maria que nos chama a atenção: braços estendidos e olhar fixo em direção a Timóteo, como que acolhendo qualquer iniciativa do outro e acompanhando o que estava sendo feito. Maria participa ativamente da cena mostrando com o corpo sua expressividade. Mesmo com poucas palavras nesse momento, ela parece se instituir como o tu que poderia instigar Timóteo a se engajar na interação e, consequentemente, colocar-se como o eu, instaurando a intersubjetividade necessária para que uma enunciação se dê, como preconiza Benveniste (2005, p. 286) ao dizer que quando um 
locutor se coloca como sujeito e instaura um Eu na língua, esse mesmo "eu propõe outra pessoa, aquela que, embora sendo exterior a "mim", torna-se o meu eco - ao qual digo tu e que me diz tu".

A conclusão de Timóteo perfaz o terceiro mo(vi)mento. No final do excerto, ao intervir na discussão, ele expõe sua conclusão a respeito da prática de speed dating: "Je crois qu'ily a des autres manières pour trouver l'âme soeur". O índice específico que aponta para a pessoa nesse enunciado é o pronome (je- eu) seguido do verbo (crois - creio) com o qual Timóteo expõe seu juízo de valor sobre o tema; os outros elementos são os procedimentos acessórios ${ }^{15}$ dos quais Timóteo se vale para influenciar os demais colegas. A forma (sintagmática) como o aluno articula o enunciado, a partir da relação interlocutiva, pode apontar para o efeito de uma tomada da palavra na língua, dada a singularidade com que o ato enunciativo foi produzido, levando em conta o jogo com a experiência de linguagem desse sujeito. Em outras palavras, esse enunciado não estava previsto no "jogo" do jeu de rôles, mas, enquanto previsto no jogo da linguagem, marca uma posição sujeito e uma inscrição desse sujeito na língua para ser dito e dizer de si. Contudo, é importante explicitar que a tomada da palavra não está necessariamente ligada ao fato de o aluno falar ou não a outra língua; o fato de falar pode ser entendido como um efeito. O ponto central é que esse evento está para além das palavras literais que podem ser ditas; ele é da ordem de uma inscrição subjetiva na língua, o que implica ser tomado por ela para poder tomá-la e enunciar-se, ainda que com poucas palavras.

Por fim, como um quarto mo(vi)mento destacamos a entrada de Gabriela na discussão. Até esse momento, as intervenções realizadas pela professora, corrigindo e emitindo alguns comentários, parecem não ter impedido o engajamento dos alunos na discussão. A ausência da palavra da professora em vários momentos parece indiciar alguns efeitos na forma como os alunos se engajam na discussão, por exemplo, se identificando a ela e aos interlocutores com os quais a troca se dá. Entretanto, com Gabriela, ocorre uma interferência que se dá diferentemente, no sentido de deslegitimar o modo como a aluna tenta tomar a palavra. Isso parece ser feito em proveito da legitimação de certa vertente normativa do que seria

\footnotetext{
${ }^{15} \mathrm{Na}$ linguística da enunciação, os procedimentos acessórios referem-se a quaisquer expedientes morfológicos, lexicais ou sintáticos de que se vale o locutor para influenciar seu interlocutor, e que conferem singularidade a cada ato de enunciação (MELLO, 2012).
} 
falar francês, colocando de lado uma intervenção que pudesse levar a aluna um pouco mais adiante em seu exercício de tomada da palavra. Utilizamos "interferência" no primeiro momento e, logo depois, "intervenção" por apreendermos esses dois termos de modos diferentes. Entendemos a interferência como sendo aquela que, em geral, se dá de modo invasivo na fala do aluno, que por sua vez mantém-se assujeitado à norma (im)posta pelo professor, não mobilizando outros recursos linguísticos (AGUSTINI; ARAÚJO; LEITE, 2013). Por sua vez, a intervenção é considerada como uma ação que se configura como aposta. Ou seja, a partir de uma tomada de posição discursivo-enunciativa, a professora intervém, de modo a desestabilizar e possibilitar deslocamentos ao aluno (GOMES, 2013). Trazemos de Leite (2015) a noção de posição discursivo-enunciativa como sendo o modo responsivo e responsável pelo qual o sujeito pode marcar uma relação discursiva com o objeto de seu discurso.

$\mathrm{Na}$ tentativa de emitir sua opinião a respeito do tema, Gabriela o faz de modo muito inseguro: "Te pense que cette chose de coeur", parecendo indicar com a entoação ascendente (como em uma indagação, mas não marcada na transcrição por não tratar-se de uma pergunta), certificar-se, primeiramente, quanto à acuidade da palavra e da pronúncia. O que vem em seguida é a correção da professora: "Du coeur". Gabriela continua a tentativa a partir da correção e o que vemos é mais uma exclamação em busca de uma confirmação: "Du coeur ne pait pas/pai??. Nesse momento da CE o diálogo instaurado entre Professora e Gabriela não nos parece fazer nenhum sentido, já que a aluna só emitiu seus comentários entoando-os como perguntas e não como assertivas que pudessem evidenciar seu posicionamento sobre o tema. Além disso, pensando na estruturação sintagmática que ela poderia promover, a aluna começa a colocar o enunciado no eixo sintagmático fazendo uso dos índices específicos e dos procedimentos acessórios da língua. A falta de mais elementos que completem esse enunciado, entretanto, nos autoriza a pensar no efeito-resistência que a aluna sofre frente à forma da língua, que se acirra via correção da professora.

A professora, como que "tateando" no dizer da aluna ("Ah... ne peutpas être?"; "Mais vous ne croyezpas!') elabora frases que imagina completar aquilo que a aluna gostaria de dizer, procedimentos discursivos muito comuns à posição de professor e do ritual enunciativo de sala de aula, mas que não teriam lugar nessa etapa da aula, uma vez que os alunos estariam em meio a um momento de produção livre, ou seja, na execução de uma tarefa. Nesse 
ponto, encerra-se a discussão com Gabriela e passa-se para outra etapa da aula sem dar tempo à aluna para emitir outro comentário. Percebemos nessa cena a dificuldade da aluna em expor sua opinião, seja pela falta da língua enquanto conhecimento sistêmico, seja por falta dela como identificação. Porém, também observamos um silenciamento dela em relação ao próprio agenciamento e diante da forma como é finalizada a discussão, limitando-a, ou cerceando-a em seu mo(vi)mento de sentidos, ou seja, limitando qualquer tentativa de enunciar-se na língua. É importante lembrar que o centro dessa discussão não é o conjunto de ações da professora, mas os efeitos de sentidos que provocam nas práticas linguageiras que visariam promover a tomada da palavra. Assim, percebemos que o ritual enunciativo de sala de aula interpela tanto professor como aluno, esvaziando qualquer traço de autenticidade, negociação, interação ou significação que pudesse estar atrelado à prática do jeu de rôle.

Outro aspecto desse quarto mo(vi)mento é o fato de Gabriela colocar a professora enquanto sua única interlocutora naquele momento, quando, em um jeu de rôle, aquele que é proposto como interlocutor é um semelhante ao aluno, ou seja, seu par. Essa atitude não foi observada nos outros mo(vi) mentos, ao contrário, os alunos estavam o tempo todo interagindo entre si, em uma troca de informações e opiniões a respeito do tema. Observamos isso na postura de Maria ao evidenciar sua empolgação a João e Timóteo e questioná-los; na postura de Timóteo, ao explicar e representar; na postura de João ao contrariar a opinião de Maria. Gabriela, no entanto, parece não estabelecer relação com os outros alunos, limitando-se apenas a elaborar frases feitas que, ainda assim, demandam a aprovação da professora. Quanto à Maria, Timóteo e João, no que se refere às análises acima, parece ter havido um forte mo(vi)mento em torno de apropriarem-se da língua, tomar a palavra, uma vez que, ao enunciar, o aluno tanto agencia a língua quanto se lança na (inter)locução com o outro. Consideramos que a enunciação aí produzida é um dos efeitos que pode indiciar a tomada da palavra na LE. Quanto à Gabriela, apesar das tentativas, observamos uma resistência dela em tomar a palavra, acirrada pelas interferências da professora, ambas tomadas pela injunção pedagógica da aula. O ritual da sala de aula parece limitar a possibilidade da aluna em colocar-se como um eu e instituir, por esse ato, um tu que configuraria um outro, instaurando, assim, uma troca em que um eco e um diálogo de fato se instituiria. 
A artificialidade e o imperativo da norma per se não constituem um impedimento para a tomada da palavra. Como foi possível observar, haverá aprendizes que se inscreverão na língua, ainda que sejam corrigidos, cerceados ou que a situação encenada pareça bastante improvável. Entretanto, para outros, essas características constitutivas do ritual enunciativo da sala de aula asseveram o confronto com a língua pela qual poderiam se deixar tomar para tomá-la e dizer de si, como indiciado pela segunda CE.

\section{CE (2)}

Timóteo e Maria (Primeira dupla de alunos a se apresentarem na sala de aula representando um contexto de speed dating)

\author{
$\boldsymbol{P}$ : Vous devez vous présenter! \\ T: Bon, Je m'appelle Jacques/Je m'appelle \\ monsieur Jacques... \\ $\boldsymbol{P}:$ Monsieur non, ça ne va pas marcher/ \\ $\boldsymbol{T}$ : Je suis très riche (risos) \\ $\boldsymbol{P}$ : Si vous voulez faire connaissance ça vas pas marcher de \\ se présenter comme monsieur/madame, non, je m'appelle \\ Jacques! \\ T: Oui/ Je m'appelle Jacques, je suis [INCOMP], \\ très riche... \\ $\boldsymbol{P}$ : très religieux \\ $\boldsymbol{T}$ : Não, só sou rico (a turma ri bastante!) ah...j'ai \\ quarante ans, je suis divorcé... je sais pas qu'est-ce que je veux \\ parler... (olha para a professora) \\ $\boldsymbol{P}:$ Je sais pas ce que je vais dire \\ $\boldsymbol{T}$ : je sais pas ce que je peux parler... \\ $\boldsymbol{P}$ : Ce que je veux parler
}

$T$ : Eu já não sei mais o que falar... Je participerais jamais de ce type de chose (risos)
$\boldsymbol{P}$ : Você deve se apresentar!

$\boldsymbol{T}$ : Bom, eu me chamo Jacques/ eu me chamo senhor Jacques..

$\boldsymbol{P}$ : Senhor não, isso não vai "rolar"/

$\boldsymbol{T}$ : Eu sou muito rico (risos)

$\boldsymbol{P}$ : Se você quiser se relacionar dessa forma não vai "rolar", se apresentar como senhor/ senhora, não, eu me chamo Jacques!

$\boldsymbol{T}$ : Sim/ eu me chamo Jacques, eu sou [INCOMP] muito rico...

$\boldsymbol{P}$ : Muito religioso

$\boldsymbol{T}$ : Não, só sou rico (a turma ri bastante!) ah... eu tenho quarenta anos, sou divorciado... eu não sei o que eu quero falar... (olha para a professora)

$\boldsymbol{P}$ : Eu não sei o que vou dizer

$\boldsymbol{T}$ : Eu não sei o que eu posso falar...

P: $O$ que en quero falar

T: Eu já não sei mais o que falar... Eu jamais participaria desse tipo de coisa (risos)

O mo(vi)mento que enfocamos nessa cena é a resistência de Timóteo em entrar no jogo, não conseguir representar, apesar de não demonstrar dificuldade em se expressar na sala de aula. Pelo contrário, ele sempre fazia questão de colocar sua opinião e discutir com os colegas e com a professora. Timóteo demonstra estar incomodado com a atividade sem saber ao certo o que deveria fazer, o que pode ser indiciado pelas repetições, hesitações e pelas informações desconexas ("ah...j'ai quarante ans, je suis divorcé"). Ele reluta na representação e não se submete às interrupções da professora, 
nem mesmo quando ela o faz para corrigi-lo. Ele diz de outro modo, mas não repete a correção feita:

T: Não, só sou rico (a turma ri bastante!) ah...j'ai quarante ans, je suis divorcé ... je sais pas qu'est-ce que je veux paler... (olha para a professora)

$\boldsymbol{P}:$ Je sais pas ce que je vais dire

$\boldsymbol{T}$ : je sais pas ce que je peux parler [...].

Essas evidências nos apontam para o quanto essa cena foi pura e simplesmente para contemplar a uma demanda do ritual da sala de aula, parte integrante do processo de aprendizagem de uma língua. Embora resistindo, Timóteo parece tomar a palavra ao falar de sua resistência à tarefa imputada, porque o faz em língua francesa e ainda resiste à correção. Não observamos na CE (2) nenhuma expressão que pudéssemos apontar como nova a partir do tema trabalhado. Ao contrário, o diálogo se mostra travado, cerceado o tempo todo pela interferência, que marca a posição discursiva da professora nesta atividade, o que é indiciado pela relutância de Timóteo diante da correção. O aluno utiliza o verbo (veux - quero) e não o (vais dire - vou dizer) como sugerido. O verbo querer está para uma relação com o todo do diálogo bem mais complexa do que simplesmente o verbo ir (aller) como auxiliar do futuro, já que o aluno insiste em desvelar algo de sua resistência em entrar nesse jogo. Ele não sabe exatamente o que "quer dizer", diferente de do que "vai dizer" (im)posto pela professora, como possível ação constitutiva de sua posição enquanto tal. Essa resistência é reiterada na reformulação de Timóteo: "je sais pas ce que je peux parler" (o que posso dizer). Nesse momento, o aluno nos introduz, a partir de sua sintagmatização, uma pluralidade de sentidos imbricados não somente nesse enunciado como em toda a cena.

Destacamos pelo menos dois sentidos que a locução verbal (peux parler-posso dizer) produz: limitação e contenção. Ou seja, é exatamente daquilo que pode ser dito em sala de aula que essa cena trata; daquilo que é possível dizer em uma situação irreal, mas encenada como autêntica e real, em que o foco é o tempo e a acuidade do que se diz e não o que se diz. O sentido de censura e cerceamento introduzido pelo verbo (pouvoir-poder) não é nada menos do que o acirramento de um discurso pedagógico que tenta estabelecer o como e o que se falar e a posição discursiva de professor que porta as marcas, as insígnias de um francês que foi eleito como sendo "correto" ou "padrão" e que tem a autoridade de direcionar e propor as situações de interação balizadas pelo material didático adotado. 
Ao sintagmatizar, Timóteo não realiza somente uma simples combinação de palavras; essa ação implica toda uma operação semântica, até mesmo lógica no interior da frase, a fim de promover determinados efeitos de sentido (MELLO, 2012). As palavras em jogo aqui são verbos; deste modo, o aluno parecia portar certo saber da língua porque se deixava tomar por ela para fazer valer sua estranheza diante da situação.

O limite para se deixar submeter ao ritual se configura na declaração: "Eu já não sei mais o que falar... Je participerais jamais de ce type de chose [risos]". O dizer é acompanhado do corpo, pois, rindo, ele se volta para a professora com as mãos para cima, reforçando o tom de questionamento. $\mathrm{O}$ efeito-resistência se inscreve, desse modo, no e pelo corpo de Timóteo, ao mesmo tempo em que corrobora a resistência que se enuncia no dizer. Ao contrário de evidenciar uma débil competência linguística para produzir a frase em questão na língua francesa, o enunciado em língua materna deixa flagrar o quanto, em alguns momentos, a incidência do materno na língua é mais forte no corpo daquele que diz. Nesse momento, no auge da discussão em que parece haver urgência em expressar-se, o que escapa é essa língua pela qual primeiro acedemos à linguagem. Embora o protesto venha primeiramente em língua materna, a decorrência que o aluno dá para a situação o inscreve na LE, como uma tentativa de instaurar um ponto final àquela situação.

Mesmo que Timóteo não tenha entrado no jogo de papéis (jeu de rôle), ele entra no jogo da língua com a professora e, dessa maneira, toma a palavra para falar de si, sem se dar conta desse efeito. Se fosse outro aluno que talvez não demonstrasse segurança com o saber da língua, a postura dele frente às interferências da professora poderia ser de silenciamento ou de repetição da forma. Esse conjunto de fatores (artificialidade da atividade, a resistência do aluno, a interferência da professora, dentre outros) pode ser responsável por acirrar a resistência do aluno em tomar a palavra neste tipo de situação, impedindo, ou mesmo dificultando, significativamente, a inscrição nessa outra língua.

\section{Tomando a palavra para concluir}

A partir da discussão dos resultados de análise, evidenciamos que o trabalho com a oralidade da forma proposta pela DLE criou entraves que dificultaram e, em alguns casos, até impediram que a tomada da palavra 
em LE ocorresse. O compromisso com o ritual da sala de aula, com a proficiência linguístico-comunicativa, com a promoção de situações que pareçam autênticas, mas se revelam improváveis, desfavorece, muitas vezes, instâncias de identificação do aprendiz com e na LE. Percebemos que, por mais que a prática de um professor se volte para propiciar momentos em que a oralidade possa ser praticada e, eventualmente, o aluno tome a palavra na língua outra, a contingência da sala de aula pode se configurar como cerceadora dos mo(vi)mentos que alguém precisa empreender para construir e se apropriar de um espaço enunciativo nessa língua. Provavelmente isso ocorra porque as ações pedagógicas em contextos de ensino visam à homogeneidade, normatização e estabilidade, enquanto a subjetividade está para a ordem do singular, do que escapa à norma, do inesperado. Entretanto, justamente devido a essa razão é que, a despeito da realidade que perfaz o trabalho com a oralidade em muitas salas de aula de língua estrangeira, podemos verificar que há aprendizes que se lançam na enunciação em LE, na medida em que se deixam subjetivar e se subjetivam pela e na LE.

Ao delimitarmos as fronteiras teóricas entre enunciação e produção oral, no sentido em que a primeira está para um processo de apropriação e de inscrição subjetiva na língua e a segunda para uma produção mecanizada do dizer, atendendo consideravelmente às exigências utilitaristas, não sugerimos que a produção oral acontece em detrimento da enunciação ou vice-versa. Ao contrário, intentamos evidenciar que um evento pressupõe o outro. Contudo, na sala de aula de LE, a produção oral parece ganhar relevância em função de poder ser comparada ao produto final ansiado pelo ensino e aprendizagem: se o aluno produziu, ele aprendeu. O próprio verbo que perfaz a expressão "produção oral" aponta para a injunção em jogo na sala de aula de línguas: o produto da aprendizagem, que, normalmente, se materializa na competência oral.

Ao traçar as relações entre questões de ordem linguística e entre aquelas que extrapolam essa relação, neste caso a possibilidade de inscrição subjetiva na língua, evidenciamos as relações de identificação (ou não) que os alunos estabelecem com e na LE. A possibilidade da tomada da palavra foi evidenciada, na medida em que foi possível perceber as marcas de apropriação da língua pelo sujeito, culminando na produção da enunciação.

Ao identificar-se com a língua, o aluno se subjetiva nela e por meio dela para enunciar. Essa ação, como evidenciamos por meio dos resultados da análise, diz respeito à apropriação da língua, de forma a propiciar que 
o sujeito a mobilize para o dizer de suas questões. Conforme ocorre o agenciamento dos elementos na língua, o sujeito vai construindo e descontruindo um espaço enunciativo na língua do outro, pondo em relação a ausência e presença desse lugar. Dado que as várias possibilidades de agenciamento da língua não se esgotam, sempre restam outras possibilidades, propiciando que o sujeito esteja em constante processo de apropriação de um espaço. A instância da tomada da palavra, como concebemos nesse trabalho, é evidenciada, portanto, a partir da produção de enunciação, pois sinaliza não somente que o aluno está sendo dito pela língua e, por isso, consegue dizer-se nela, como denuncia o fato de o aluno ter se colocado como sujeito, se assujeitando a uma posição discursivo-enunciativa na língua do outro.

Essas considerações apontam para que o trabalho com a oralidade em LE enseje o aspecto contingencial e provisório que existe na enunciação e, por consequência, na tomada da palavra. O caráter subjetivo e intersubjetivo que envolve a enunciação pode ser considerado pelos professores, a fim de possibilitar que os envolvidos se posicionem discursivamente, ainda que expostos a uma atividade meramente artificial que não possibilitaria a instância da tomada da palavra. Além disso, as interferências que visam pura e simplesmente a acuidade do dizer e o uso formal da língua mediante padrões preestabelecidos pelo professor podem ser revistos, de modo a amenizar o caráter de cerceamento e normatização das ações pedagógicas, favorecendo que o aluno se posicione frente à instância de discurso que a ele se coloca na LE.

\section{Agradecimentos}

Agradecemos à CAPES, pela bolsa de fomento, e ao Programa CASADINHO/PROCAD, que propiciou as interlocuções necessárias à execução desta pesquisa.

\section{Contribuição das autoras}

Isabel Silva Alves Quintino: proposta da pesquisa, coleta de dados, esboço de análise dos dados, considerações finais. Carla Nunes Vieira Tavares: aprofundamento do desenho do artigo, desenvolvimento do arcabouço teórico, análise dos dados, considerações finais 


\section{Referências}

AGUSTINI, C.; ARAÚJO, E. D.; LEITE, J. D. Rasuras em manuscritos escolares e implicações enunciativas: da projeção de (inter)locução à transmissibilidade. Revista Letras e Letras, Uberlândia, v. 29, n. 1, p. 1-20, 2013.

ANDERSON, P. La didactique des langues étrangères à l'épreuve du sujet. Besançon: Presses Universitaires Franc-Comtoises, 1999. 375p.

BENVENISTE, E. Problemas de Linguistica Geral I. Campinas: Ed. Pontes, 2005. 295p.

BENVENISTE, E. Problemas de Linguística Geral II. Campinas: Ed. Pontes, 2006. 356p.

BENTO, M. La perspective actionnelle dans les manuels de langue au collège: recherches en didactiques. Cabiers Théodile - Recherches en Didactiques, Paris, v. 15, n.1, p. 61-89, 2013.

CECR. Cadre Européen Commun de Référence pour les langues: Apprendre, Enseigner, Évaluer. Conseil de la Coopération Culturelle, Comité de l'Education, Division de Langues Vivantes. Strasbourg, FR, 2000.

CORACINI, M. J. (Org.). O jogo discursivo na aula de leitura: língua materna e língua estrangeira. 2. ed. Campinas: Pontes, 2002.141p.

DE NARDI, F. S. Outros dizeres sobre o ensino de segunda língua: um lugar para a tomada da palavra no terreno da opacidade e do real. 2002. 152f. Dissertação (Mestrado em Teorias do Texto e do Discurso) - Universidade Federal do Rio Grande do Sul, Porto Alegre, 2002.

FRANZONI, P. H. Nos bastidores da "Comunicação Autêntica": uma reflexão em linguística aplicada. 1991. 106f. Dissertação (Mestrado em Linguística Aplicada) Universidade Estadual de Campinas, Campinas, 1991.

GERMAIN, C. Évolution de l'enseignement des langues: 5000 ans d'histoire. Paris: CLE International, 1993.350p.

GOMES, V. A. A intervenção do professor no processo de construção da escrita: um olhar sobre o aluno com "dificuldades de aprendizagem". 2013. 255f. Tese (Doutorado em Estudos Linguísticos) - Universidade Federal de Uberlândia, Uberlândia, 2013.

LEITE, J. D. Aula de língua portuguesa: das identificações do professor à sua prática. 2015. 248 f. Tese (Doutorado em Linguística Letras e Artes) - Universidade Federal de Uberlândia, Uberlândia, 2015.

MELLO, V. H. D. A sintagmatização-semantização: uma proposta de análise de texto. 2012. 145f. Tese (Doutorado em Teorias do Texto e do Discurso) - Universidade Federal do Rio Grande do Sul, Porto Alegre, 2012. 
MOREIRA, M. A. Aprendiragem significativa: a teoria de David Ausubel. São Paulo: Moraes, 1982. 182p.

PECCHEUX, M. Discurso: estrutura on acontecimento. Trad. Eni P. Orlandi. Campinas: Pontes Editores, 2012. 68p.

PÊCHEUX, M.; FUCHS, C. A propósito da análise automática do discurso: atualização e perspectivas. In: GADET, F.; HAK, T. (Org.). Por uma análise automática do discurso: uma introdução à obra de Michel Pêcheux. 3. ed. Campinas: Edditora da Unicamp, 1997. p. 163-252.

PUREN, C. Perspectives actionnelles et perspectives culturelles en didactique des langues-cultures: vers une perspective co-actionnelle co-culturelle. Les Langues Modernes, Paris, n. 3, p. 55-71, jul.-set. 2002.

REVUZ, C. A Língua Estrangeira entre o desejo de um outro lugar e o risco do exílio. In: SIGNORINI, I. (Org.). Lingua(gem) e identidade: elementos para uma discussão no campo aplicado. Campinas: Mercado de Letras, 2001. p. 213-230.

ROSEN, É. La perspective actionnelle et l'approche par les tâches. Le Français Dans Le Monde: Recherches et Applications, Paris, n. 45, p. 6-14, jan. 2009.

SANTOS, P. S.; GUILHERME, M. F. F. Inscrições discursivas sobre competência oral em lingua inglesa em contexto de aula de conversação. Horizonte Científico, Uberlândia, v. 5, p. 1-25, 2011.

SERRANI, S. Singularidade discursiva na enunciação em segundas línguas. Cadernos de Estudos Linguisticos, Campinas, v. 38, p. 109-120, jan.- jun. 2000. DOI: https:// doi.org/10.20396/cel.v38i0.8636964

TAVARES, C. N. V. Entre o desejo e realização? Caminhos e (des)caminhos na aprendizagem de uma língua estrangeira. 2002. 201f. Dissertação (Mestrado em Lingüística) - Instituto de Letras e Linguística, Universidade Federal de Uberlândia, Uberlândia, 2002.

TRIM, J. L. M. Progress towards a more comprehensive framework for the definition of language-learning objectives. In: VAN EK, J.; TRIM, J. L. M. (Org.). Across the threshold: readings from the modern languages projects of the Council of Europe. Oxford: Pergamon Press, 1984. p. 123-128.

VALÉRIO, K. M.; MATTOS, A. M. A. Critical Literacy and the Communicative Approach: gaps and intersections. Revista Brasileira de Linguistica Aplicada, Belo Horizonte, v. 18, n. 2, p. 313-338, 2018. DOI: http://dx.doi.org/10.1590/19846398201812252 


\section{APÊNDICE}

QUADRO 1 - Convenções de transcrição utilizadas neste trabalho para a transcrição das filmagens em sala de aula

SINAL

/

[INCOMP]

Negrito

PALAVRA EM CAIXA ALTA

PALAVRA EM CAIXA ALTA

$\mathbf{P}$

\section{SIGNIFICADO}

Pausa curta

Prolongamento de vogal

Trecho Incompreensível

Refere-se aos destaques das pesquisadoras

Refere-se aos "erros" que os alunos cometeram

Refere-se às correções feitas tanto pelas alunas quanto pela professora

Professora

Data de submissão: 28/06/2018. Data de aprovação: 30/11/2018. 